\title{
PENGARUH MODEL PEMBELAJARAN EXAMPLE NON EXAMPLE TERHADAP HASIL BELAJAR PESERTA DIDIK
}

\author{
Yuliana $^{1}$, Sunarwin ${ }^{2}$, Kartini Rahman Nisa ${ }^{3}$ \\ Program Studi Pendidikan Kimia Fakultas Pendidikan Matematika Dan IPA IKIP \\ Muhammadiyah Maumere \\ Email:annayuliana564@gmail.com,Soenarwin2011@gmail.com, \\ Kartinirahmannisa@gmail.com
}

\begin{abstract}
The research aimed to know the effect of example non example model of students learning outcomes with acid base solution subject at theMAS At-Taqwa Beru in even semesterof the 2020-2021 academic year. Pre-experiment used as research method with one group pre-test post-test as the research design. The studyused population from students of class XI MIA MAS At-Taqwa Beru, and used purposif sampling method, so class XI MIA which are 18 students were a research sample. Data analysis using $t_{\text {count }}$ test, and first, descriptive statistical analysis and data requirements testing. Data requirements test results, where the data is normal and homogeneous. Based on the testing of the hypothesis carried out, obtained $t_{\text {count }}$ of 3,6920 and $t_{\text {table }}$ of 1,6957. The results $t_{\text {count }}>t_{\text {table }}$, so $H_{0}$ is rejected and $H_{1}$ is accepted. The conclusion of this research was theexample non example model influenced student learning outcomes.
\end{abstract}

Keywords: Example Non Example, Learning Outcomes.

\section{PENDAHULUAN}

Masalah pendidikan sangat erat kaitannya dengan upaya manusia dalam perencanaan untuk mewujudkan kondisi belajar mengajar yang mampu mendukung siswa lebih berperan dalam pengembangan dirinya sehingga memiliki karakteristik individu yang terampil, berkepribadian dan berkarakteristik cerdas, memiliki akhlak yang mulia, kekuatan spiritual keagamaan yang baik, serta mampu dalam pengendalian diri yang diperlukan dalam berkehidupan bermasyarakat, berbangsa dan bernegara, yang mana mengacu pada UU RI No. 20 Tahun 2003 mengenai Sistem Pendidikan Nasional.

Guru ialah individu yang memiliki peran yang sangat signifikan bagi perkembangan dan peningkatan peserta didik dalam dunia pendidikan. Pada dasarnya, aktivitas disekolah memang melibatkan pendidik dan peserta didik, karena cara perkembangan diri dan pengoptimalan bakat serta kemampuan siswa terjadi selama proses pembelajaran tersebut. Seorang guru berkewajiban untuk mengembangakan potensi diri peserta didik dengan membimbingserta menyampaikan ilmu pengetahuan yang dimilikinya kepada siswa atau anak didiknya. Peran guru tersebut diyakini dapat mewujudkan peserta didik yang berkualitas yang dilakukan melalui kegiatan pembelajaran yang berkualitas pula (Habel, 2015). Akibat dari peran tersebut, salah satu hal yang paling menentukan dalam pengembangan peserta didik yaitu melakukan pengembangan pada model pembelajaran di kelas.

Pengembangan model pembelajaran merupakan inovasi tugas mengajar guru yang tergambar pada sajian pengajaran yang unik dan disesuaikan dengan kondisi lingkungan pembelajaran tersebut. Akan tetapi, dalam inovasi penggunaan model pembelajaran ini, guru harus tetap memperhatikan materimaterinya sebabtidak seluruhnya materi bisa diajarkan kepada siswa. Jadi supaya proses pembelajaran khususnya pada mata pelajaran Kimia dapat dipahami oleh peserta didik dan berlangsung tidak membosankan serta adanya efektif serta efisiensi yang baik dalam proses belajar mengajar.

Inovasi dalam pembelajaran Kimia faktanya sangat dibutuhkan, karena rendahnya 
daya serap peserta didik mengenai mata pelajaran ini. Hal tersebut disebabkan oleh pemahaman guru yang cenderung menitikberatkan pembelajaran yang menggunakan cara hafalan yang terkesan membuat peserta didik semakin pasif dan tidak termotivasi agar melakukan aktifitas yang kreatif dan melakukan penalaran yang lebih otentik. Sejatinya, proses pembelajaran yang disebutkan dalam UU Sisdiknas mengarah pada gaya belajar mengajar dengan student center atau peserta didik lebih aktif dibandingkan guru. Namun, agaknya gaya pembelajaran ini masih kurang diterapkan, sehingga terkesan bersifat konvensional, dimana guru masih memegang peran center dalam kelas, baik dalam penentuan isi materi maupun langkah-langkah pembelajaran, sehingga mempengaruhi kesungguhansiswa dalam cara belajar mengajar serta cenderung bergantung kepada pendidik, yaitu siswa lebih banyak mendengar guru berceramah, adanya tanya jawab, sedikit diskusi dan berakhir dengan penugasan sesuai materi yang diajarkan. Akibatnya, peserta didik menilai pembelajaran Kimia justru membosankan dan tidak menarik untuk dipelajari.

Berdasarkan hasil interview dengan guru Kimia di MAS At-Taqwa Berudapat diketahui bahwa rata-rata nilai kimia parasiswa sangatlah rendah. Hasilreratanilai ulangan tengah semester sangat rendah.Hal ini dapat dikarenakanKimia termasuk mata pelajaran yang bersifat abstrak, serta contoh yang diberikan guru tidak terlalu jelas, sehingga membutuhkan keterlibatan guru secara lebih komunikatif dalam menjelaskan model pembelajaran. Oleh sebab itu, peneliti mencoba mengimplementasikan strategi pembelajaran dalam mendukung proses pembelajaran yang tentunya diharapkan mampu mendorong minat peserta didik dalam mempelajari kimia.

\section{METODE PENELITIAN}

Pelaksanaan penelitian berada di kelas XI MIA MAS At-Taqwa Beru di semester genap tahun pelajaran 2020/2021, dan padabulan Januari - Februari 2020. Sampel penelitiannya adalah semua pesertadidik kelas XI MIA MAS At-Taqwa Beru yang berjumlah 18 orang.

Penelitian ini menggunakan metode penelitian pre experimen, dimana subjek penelitian yang digunakan yaitu siswa satu kelas tanpa menggunakan kelas kontrol atau pembanding. Metode penelitian pre eksperimen sesuai dengan tujuan penelitian yaitu agar dapat menilai pengaruh implementasibelajar example non example pada peningkatan hasil belajar peserta didik, yakni melalui pembandingan hasil eksperimen Pre-test dan Post-test setelah mengimplementasikan model pembelajaran.

Sejalan dengan metode penelitian pre experimen, maka teknik untuk mengumpulkan data harus memperhatikan serta memberikan tes hasil belajar siswa yang mendapat perlakuan sebelum dan sesudah penggunaan model pembelajaran ini.

\section{HASIL DAN PEMBAHASAN}

\section{Hasil Penelitian}

1. Tes awal

Pemberian tes ini kepada peserta didik merupakan langkah awaal yang dilakukan pada saat penelitian sebelum dilakukannya treatment. Pada perlakuan ini, tes yang dilakukan yaitu tes hasil belajar berupa tes uraian objektif mengenai materi asam basa yang dikerjakan oleh 18 peserta didik XI MIA. Berdasarkan tes tersebut hasil yang diperoleh ditunjukkan daribagan.

Bagansatu Nilai Tes Awal (pre test)

\begin{tabular}{cccccc}
\hline \multirow{N}{*}{ N } & Nilai & Nilai & $\overline{\bar{X}}$ & $\mathrm{~V}$ & SD \\
& Terendah & Tertinggi & & & \\
\hline 18 & 53 & 80 & 61,083 & 88,7714 & 9,421 \\
\hline
\end{tabular}


Berlandaskan pada hasil nilai siswa yang ditunjukkan pada Tabel 1, maka diperoleh nilai maksimum pada tes awal adalah 80 dan nilai minimum pada tes awal yaitu 53, nilai rata-ratanya yaitu 61,083 dan standar deviasinya yaitu 9,421 .

Tabel 2. Hasil belajar sebelum perlakuan (pre-test)

Berdasarkan tabel distribusi hasil pre-

\begin{tabular}{|l|l|l|}
\hline Nilai & Frekuensi & Kelas interval \\
\hline $53-58$ & 2 & $52,5-58,2$ \\
\hline $59-63$ & 3 & $58,5-63,5$ \\
\hline $64-69$ & 5 & $63,5-69,5$ \\
\hline $70-75$ & 6 & $69,5-75,5$ \\
\hline $76-81$ & 2 & $75,5-81,5$ \\
\hline$\sum$ & 18 & \\
\hline
\end{tabular}

test, maka dapat dibuat histogram frekuensi

hasil pre-test.

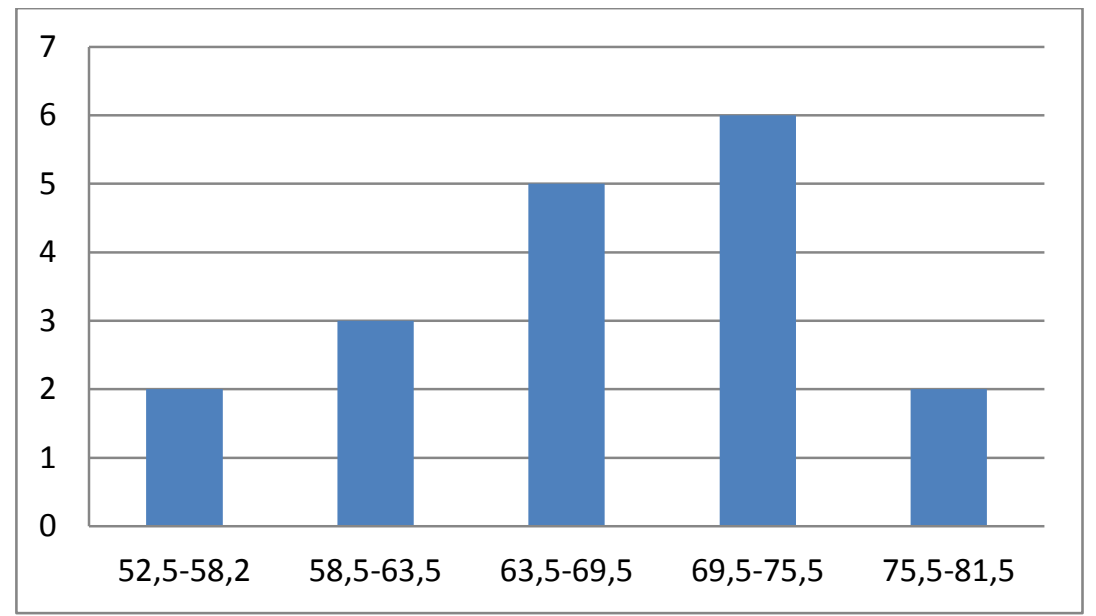

Gambar 1. Grafik Histogram Hasil Belajar Sebelum Perlakuan (pre-test)

Dari grafik dan tabel di atas hasil frekuensi pre-test kelas interval tertinggi 69,5-75,5 sebanyak 6 peserta didik sedangkan kelas interval yang paling rendah atau sedikit terletak pada kelas interval 75,5-81,5 sebanyak 1 peserta didik.

\section{Post-Test (Test Akhir)}

Pemberian perlakuan yaitupost-test (tes akhir) pada siswa merupakan langkah akhir yang dilakukan pada saat penelitian sesudah dilakukannya treatment. Pada perlakuan ini, tes yang dilakukan yaitu berupa tes uraian objektif mengenai sifat asam basa yang dikerjakan oleh 18 orang peserta didik kelas XI MIA. Berdasarkan tes tersebut hasil yang diperoleh dapat disajikan seperti Tabel 3.

Tabel 3. Nilai Tes akhir (post-test)

\begin{tabular}{llllll}
\hline $\mathrm{N}$ & Nilai & Nilai & $\overline{\mathrm{X}}$ & $\mathrm{V}$ & $\mathrm{SD}$
\end{tabular}




\begin{tabular}{lccccc}
\hline \multicolumn{1}{c}{ terendah } & tertinggi & & \\
\hline 18 & 59 & 86 & 67,138 & 48,8834 & 6,991 \\
\hline
\end{tabular}

Berlandaskan pada hasil nilai siswa pada Tabel 3 , maka didapatkan nilai maksimum pada tes akhir adalah 86 dan nilai minimum pada tes akhir adalah 59 dengan nilai rata-rata yang diperoleh 67,138 dan standar deviasinya 6,991 .

Tabel 4. Hasil belajar setelah perlakuan (posttest)

\begin{tabular}{|l|l|l|}
\hline Nilai & Frekuensi & Kelas interval \\
\hline $59-64$ & 9 & $58,5-64,5$ \\
\hline $65-70$ & 4 & $64,5-70,5$ \\
\hline $71-76$ & 3 & $70,5-76,5$ \\
\hline $77-82$ & 1 & $76,582,5$ \\
\hline $83-88$ & 1 & $82,5-88,5$ \\
\hline$\sum$ & 18 & \\
\hline
\end{tabular}

Berdasarkan tabel distribusi hasil posttest, maka dapat dibuat histogram frekuensi hasil post-test.

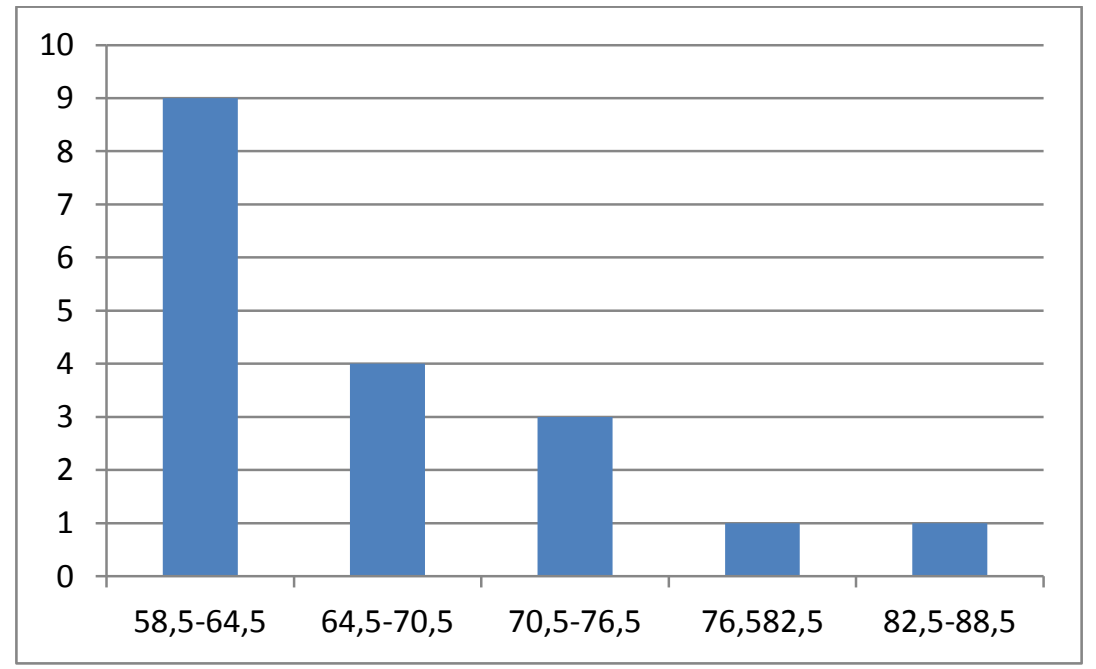

Gambar 2. Grafik Histogram hasil belajar sebelum perlakuan (post-test) 
Dari grafik dan tabel di atas hasil frekuensi post-test kelas interval tertinggi 58,5-64,5 sebanyak 9 peserta didik sedangkan kelas interval yang paling rendah atau sedikit terletak pada kelas interval 82,5-88,5 sebanyak 1 pesrta didik.

\section{Uji Prasyarat Analisis}

1. Uji Normalitas

Hasil pengujian normalitas melalui uji chi-kuadrat.

Tabel 5. Hasil Perhitungan Uji Normalitas

\begin{tabular}{ccccccccc}
\hline Tes & $\alpha$ & $\mathrm{N}$ & $\overline{\mathrm{X}}$ & $\mathrm{Sd}$ & $\mathrm{Dk}$ & $\chi_{\text {hitung }}^{2}$ & $\chi_{\text {tabel }}^{2}$ & Kesimpulan \\
\hline Pre-test & & & 61,086 & 9,421 & & 2,629 & & Normal \\
Post-tes & 0,05 & 18 & 67,138 & 6,991 & & 3,085 & & Normal \\
\hline
\end{tabular}

2. Uji Homogenitas

Tabel 6. Hasil Perhitungan Uji Homogenitas

\begin{tabular}{cccccccc}
\hline Tes & $\mathrm{A}$ & $\mathrm{n}$ & $\mathrm{Sd}$ & $\mathrm{V}$ & $\mathrm{F}_{\text {hitung }}$ & $\mathrm{F}_{\text {tabel }}$ & Kesimpulan \\
\hline Pre-test & & & 9,421 & 88,7714 & & & Homogen \\
Post-test & 0,05 & 18 & 6,991 & 48,8834 & 1,815 & 2,275 & Homogen
\end{tabular}

Data yang dianalis berupa perbandingan nilai pre-test dengan posttest. Untuk uji hipotesis penelitian yang telah dirumuskan, maka selanjutnya harus dihitung dengan uji t. Hasil pengujian $t$ ditunjukkan pada Tabel 7.

Tabel 7. Hasil Perhitungan Uji t

\begin{tabular}{lccccccc}
\hline Tes & $\mathrm{A}$ & $\mathrm{N}$ & $\mathrm{Sd}$ & $\mathrm{V}$ & $\mathrm{t}_{\text {hitung }}$ & $\mathrm{t}_{\text {tabel }}$ & Kesimpulan \\
\hline re-test & & & 9,421 & 88,7741 & & & $\mathrm{H}_{0}$ ditolak \\
sst-test & 0,05 & 18 & 6,991 & 48,8834 & 3,6920 & 2,039 & \\
& & & & & & & $\mathrm{H}_{1}$ diterima \\
\hline
\end{tabular}

Hasil perhitungan diperoleh harga $t_{\text {hitung }}$ sebesar 3,6920 dan harga $t_{\text {tabel }}$ sebesar 2,039 pada $\alpha$ sebesar 0,05 dengan derajat kebebasan sebesar 34 . Karena $t_{\text {hitung }} 3,6920>t_{\text {tabel }}$ 2,039 maka disimpulkan apabila hasil $\mathrm{H}_{0}$ ditolak yang artinya implementasi teknikpraktekexample non example mempengaruhi pencapaianpembelajaran kimia peserta didik.

\section{PEMBAHASAN}

Pengujian atas hipotesis yang dilakukan melalui uji $\mathrm{t}$ mengindikasikan bahwa $\mathrm{H}_{0}$ ditolak yakni nilai $\mathrm{t}_{\text {hitung }} 3,6920>\mathrm{t}_{\text {tabel }}$
2,039 yang artinya bentuk pembelajaran example non examplebisa mempengaruhi pencapaianpembelajaran. dan demikian, pencapaian tersebut dapat diketahui apabila inovasi belajar model example non examplemempengaruhi

pencapaianpembelajaran kimia peserta didik.

Eksperimen tersebut termasuk PreExperimental, dan desain penelitiannya menggunakan satu kelompok pre-test post-test pada siswa satu kelas XI dengan mengimplementasikan teknik belajar example non example.eksperimen tersebut ditujukan agar bisa menilai pengaruh implementasi teknik belajarexampel non example pada pencapaianpembelajaranpeserta didik. Hasil studi mengindikasikan adanya peningkatan hasil belajar kimia saat guru 
mengimplementasikan pembelajaran ini. Penerapan model pembelajaran ini dinilai dapat menadikan para siswa lebih aktif selamapembelajaran dan banyak pengalaman belajar melalui motivasi yang dibuat masingmasing siswa. Siswa dapat menumbuhkan sikap kerja sama yang baik antar teman kelas, memiliki tanggung jawab serta gotong royong dalam pemecahan suatu masalah (problem solving)sehingga memperoleh hasil belajar kimia oleh siswa secara optimal.

Adapun keunggulan pelaksanaan pembelajaran example non example di kelas yakni dapat menstimulus para siswa untuk lebih aktif selama proses pembelajaran, dan saling berinteraksi selama berada dikelas sehingga peserta didik memiliki banyak pengalaman belajar dan memiliki pemahaman terhadap konsep materi dengan lebih baik bukan hanya sekadar menghafal. Selain itu, dengan pola pembelajaran dengan penerapan metode example non example peserta didik dapat berpengaruh terhadap peningkatan sikap tanggung jawab, gotong royong, serta mau bekerja sama dalam upaya problem solving pada mata pelajaran Kimia. Keunggulan tersebut mempengaruhi hasil belajar peserta didik secara optimal dalam upaya pemahaman materi Kimia. Temuan hasil penelitian ini juga didukung oleh studi empiris Desy Apriani Siregar (2014) mengenai pengaruh penggunaan gaya pembelajaran examples bukan examplespada keterampilan mengarang puisi siswa dimana hasil penelitian menunjukkan apabila tanpa perlakuan penerapan model pembelajaran examples non examples, keterampilan peserta didik untuk menulis puisi berada pada level"cukup" dengan rerata-rata nilainya 68,1 . Sementara itu, saat penerapan model atau gaya diterapkan rentang kategori meningkat dari nilai rata-rata 68,1 menjadi nilai rata-rata 78, dengan kriteria dan kategori baik. Selanjutnya, hipotesis yang diuji menunjukkan taraf signifikan, yaitu $\alpha=$ 0,05 dengan nilai $t_{\text {hitung }}>t_{\text {tabel }}$ atau $6,18>$ 2,01.Berdasarkan hasil uji hipotesis di atas, maka telahterbukti apabila Ho ditolak dan Haditerima.

Pada perlakuan siswa dalam implementasi model pembelajaran example non example nilai rata-ratanilaites dalam materi asam-basa oleh peserta didik meningkat, hal ini menunjukan bahwa siswalebih dapat mengerti serta memahami konsep-konsep asam-basa yang diajarkan. Hasil analisis data pada pengujian hipotesis memperkuat bahwa bentuk pembelajaran example non examplemempengaruhi secara signifikan pada pemahaman siswa. Hal itu juga dibuktikan dengan keberhasilan penerapan model pembelajaran tersebut pada yang ditemukan oleh peneliti terdahulu.

Berdasarkan hasil uji-t pada pengujian hipotesis penelitian tersebut dapat diketahui apabila $\mathrm{H}_{0}$ (hipotesis nihil) ditolak, hal ini berartimodel pembelajaran Examples non Examples mempengaruhi hasil belajarsiswadalam pelajaran kimia kelasXI MIA.Dengan demikian,kesimpulannya bahwaimplementasi teknikbelajarExamples non Examples mempengaruhi hasil belajar peserta didikpada pelajaran kimia kelas XI MIA.

\section{SIMPULAN}

Berlandaskan pada pencapaian dengan pembahasan tersebutsudah dijabarkan tersebut, maka hasil penelitian ini ber implementasimodel example non examplepadahasilpembelajaran mengajar pada kelompok bisa mengasihtantaganpada hasil belajar peserta didik terhadap materi asam basa.

\section{REFERENSI}

Aunurrahman. 2014. Belajar dan Pembelajaran. Bandung: Alfabeta.

Fathurrohman, Muhammad. 2015. Modelmodel Pembelajaran Inovatif. Yogyakarta: Ar-ruzz Media.

Hamdayana, Jumanta. 2014. Model dan Metode Pembelajaran Kreatif dan Berkarakter. Jakarta: Ghalia Indonesia.

Hamiyah, N., and M. Jauhar. 2014. Strategi Belajar-Mengajar di Kelas. Jakarta: Prestasi Pustaka.

Kindy, Nurul. 2015. Perbandingan Model Pembelajaran Jigsaw dengan Group Investigation Untuk Meningkatkan Hasil Belajar Peserta didik Pada Sub Konsep Sistem Indera. Skripsi pada 
S.Pd. Unpas Bandung: Tidak diterbitkan.

Kurniasi. 2015. Model Pembelajaran. Yogyakarta: Kata Pena.

Kurniasi, Imas, and Berlin Sani. 2015. Ragam Pengembangan Model Pembelajaran. Jogjakarta: PT Kata Pena.

Shoimin, Aris. 2014. 68 Model Pembelajaran INOVATIF dalam Kurikulum 2013. Yogyakarta: Ar-ruzz Media.
Siregar, Desy Apriani. 2014. "Pengaruh Model

Pembelajaran Examples Non

Examples Terhadap Kemampuan Menulis Puisi oleh Siswa Kelas X SMA Negeri 1 Kampung Rakyat Tahun Pembelajaran 2013/2014."Basastra, Vol. 3, No. 3 111.

Susanto, Ahmad. 2014. Teori Belajar dan Pembelajaran di Sekolah Dasar. Jakarta: Kencana Prenada Media Group. 